\title{
Migração de polimorfonucleares e expressão de COX-2 no tecido endometrial de éguas susceptíveis à endometrite tratadas com plasma rico em plaquetas
}

Lorenzo Garrido Segabinazzi", Aime Friso, André Maciel Crespilho, Jose Antonio Dell Aqua Jr, Frederico Ozanam Papa, Marco Antonio Alvarenga

Universidade Estadual Paulista (UNESP), Botucatu, SP, Brasil

*Autor correspondente

e-mail: lgseg@hotmail.com

\section{Resumo}

A endometrite persistente pós-cobertura (EPPC) é uma enfermidade com impactos importantes dentro do mercado de equinos, sendo considerada a principal causa de subfertilidade nas fêmeas. Com o intuito de reduzir a resposta inflamatória, estudos recentes têm demonstrado aumento da fertilidade de animais acometidos por EPPC quando utilizadas drogas imunomoduladoras. Um modulador da resposta inflamatória que vem sendo largamente utilizado na medicina veterinária é o plasma rico em plaquetas (PRP), que contém diversos fatores de crescimento importantes na reparação tecidual, com ação benéfica no tratamento de inflamações tendíneas e osteoarticulares. Neste contexto, o presente estudo teve por objetivo avaliar o efeito do tratamento, assim como o melhor momento da aplicação de PRP sobre a resposta inflamatória uterina pós-cobertura e os índices de fertilidade de éguas susceptíveis a EPPC. Para isto, 13 éguas susceptíveis à EPPC foram utilizadas em três ciclos consecutivos. As éguas eram inseminadas com sêmen fresco de um garanhão de fertilidade conhecido 24 h após a indução da ovulação (1 mg acetato de deslorelina) e os ciclos foram classificados em: Controle (C), sem interferência farmacológica; Pré-IA, infusão intrauterina de 20 mL de PRP 24 horas antes da IA; Pós-IA, infusão intrauterina de 20 mL de PRP 4 horas após a IA. A obtenção do PRP foi realizada através de única centrifugação (120 x g/10 min) do sangue total e apenas amostras contendo mais de 250.000 plaquetas/ $\mu$ L foram utilizadas. Foram realizadas biópsias endometriais 24 horas após a IA para as análises do número de polimorfonucleares (PMN) do tecido endometrial e número de células marcadas para COX-2, avaliadas através de imunohistoquímica e classificadas através de um score de marcação (negativa; fraca; média; intensa). Variáveis contínuas foram avaliadas através de análise de variância, considerando $\mathrm{P} \leq 0,05$. Na contagem de $\mathrm{PMN}$ no estrato compacto e epitélio luminal não foi observada $(\mathrm{P}>0,05)$ diminuição nas biópsias do ciclo Pós-IA em comparação ao ciclo controle, porém quando comparado o ciclo controle ao ciclo Pré-IA foi observada tendência estatística $(p=0,063)$ para 
redução do número dessas células nas biópsias endometriais do grupo tratado com PRP. Já na contagem de PMN no estrato esponjoso, ambos os tratamentos com PRP foram eficientes $(\mathrm{P}<0,05)$ na diminuição da contagem de PMN quando comparados ao ciclo não tratado. 0 PRP também se mostrou eficiente em diminuir $(\mathrm{P}<0,05)$ a expressão de COX-2 em ambos os grupos tratados (média) quando comparados ao controle (intensa). Entre os ciclos tratados não foram observadas diferenças ( $\mathrm{P}>0.05)$ em nenhuma das variáveis estudadas. Desta forma, podemos concluir que ambos os tratamentos com PRP foram capazes de reduzir o processo inflamatório no útero de éguas susceptíveis à endometrite, com resultados similares entre os tratamentos.

Palavras-chave: Plasma rico em plaquetas. Endometrite. Égua. 